\title{
Microstructure and Microsegregation Characterization of Laser Surfaced Remelted Al- 3wt\%Cu Alloys
}

Zhenjie Yao ( $\nabla$ ycollin@umich.edu )

University of Michigan

\section{Wenjing Ren}

University of Michigan

John Allison

University of Michigan

\section{Research Article}

Keywords: Microstructure, Microsegregation, Laser Surfaced

Posted Date: October 26th, 2021

DOl: https://doi.org/10.21203/rs.3.rs-1002008/v1

License: (c) (i) This work is licensed under a Creative Commons Attribution 4.0 International License.

Read Full License 


\section{Abstract}

Solidification rates during laser remelting of solid metals occur under solidification conditions that are far from equilibrium conditions. The microstructural evolution and microsegregation behaviors are affected by these conditions. This study comprised an experimental characterization of the ultra-fine microstructure and microsegregation in laser surface remelted regions of a hypoeutectic Al-Cu alloy. The laser scan speed, which controls the cooling rate within the remelted region, was observed to have a significant effect on microstructural features and microsegregation. Dendrite arm spacing was determined to decrease with increasing scan speed and depended on location within the melt pool. A transition of the dendrite morphology was also observed in the melt pools. This transition, which is attributed to the grain orientation change influenced by the laser beam movement, was experimentally characterized. The measured microsegregation profiles show decreasing microsegregation as cooling rate increases which is typically of increasing undercooling and non-equilibrium solidification.

\section{Introduction}

Laser surface remelting (LSR) is a unique technique to achieve an ultra-fast solidification condition within the thin melted region at the sample surface. The cooling rate in the LSR experiment can achieve $10^{3}$ $10^{8} \mathrm{C} / \mathrm{s}$ [1]. This rapid solidification rate will generate nanoscale microstructural features are not formed in traditional castings [2]. The LSR technique can also improve the mechanical response in the refined region $[3,4]$. At such high solidification rates the conditions are far from equilibrium and the microsegregation behavior is significantly changed [5].

Previous experimental studies demonstrated the microstructure refinement by LSR in Al-Cu eutectic

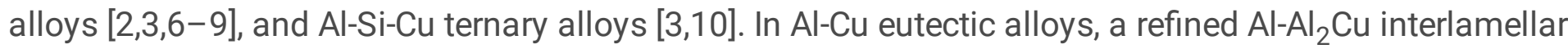
spacing as low as $17 \mathrm{~nm}$ has been observed in the laser-treated region [2]. Numerical simulation methods, such as phase field, have been able to predict the morphology evolution and microstructural quantities within the melt pool at high solidification rates [11-14]. However, few LSR studies have focused on Al-Cu alloys with low $\mathrm{Cu}$ concentration [15-17]. A quantitative characterization of the microstructure in the LSR melt pool in dilute Al-Cu alloys would be helpful to understand the effects of the laser parameters on the microstructure and provide experimental validation for future simulations of microstructural evolution during LSR. A transition of the dendrite morphology was previously observed in the melt pool from the LSR experiments [18].

Non-equilibrium partitioning at high solidification rates was observed in the previous experimental study of the laser-melted alloys [7,19-21]. The high solidification front velocity increases the solute trapping and therefore decreases the microsegregation. Limited information exists on solute redistribution during laser surface remelting [22] and characterization of microsegregation behavior in laser-melted Al-Cu alloys is missing in the literature. 
In this study, an Al-3wt\%Cu binary alloy was surface remelted under different laser conditions. The investigation was focused on a thorough microstructural characterization and a quantitative measurement of microsegregation behavior in the melted region. The goal is to provide experimental characterization of the microstructure and microsegregation far from equilibrium; and to understand the effects of laser scan speeds on those two quantities. In addition, experimental characterization was conducted to better explain the transition of the dendrite morphology in the melt pool.

\section{Material And Experimental Preparation}

\section{Materials preparation and laser experiment setting}

Plates with dimensions of 6" $\times 6 "$ " 1 1" (length $\mathrm{x}$ width $\mathrm{x}$ thickness) of Al-3wt\%Cu were cast in sand-molds and solution treated at $400{ }^{\circ} \mathrm{C}$ for 48 hours to ensure compositional uniformity throughout the plates. The solution treated plates were sectioned into 3 " $\times 1$ " $\times 0.16$ " samples, as illustrated in Figure 1 (a), for the laser surface remelting experiments. The sample size was designed to be attached to the stage during the laser remelting, and the thin samples were able to dissipate energy quickly to avoid continuing heating of the sample after the experiment. The sample surface was ground using coarse grid (600 grit) sandpaper before the experiment to remove any oxidized layer on the surface and increase the absorption rate of laser energy during the laser scan.

The samples were laser surface remelted using a solid-state disk laser (TRUMPF Laser HLD 4002). The laser was set at a wavelength of $1030 \mathrm{~nm}$, spot diameter of $0.6 \mathrm{~mm}$, and power of $2000 \mathrm{~W}$. Laser surface remelting was conducted at a range of scan speeds, including $3 \mathrm{~mm} / \mathrm{s}, 5 \mathrm{~mm} / \mathrm{s}, 15 \mathrm{~mm} / \mathrm{s}, 30 \mathrm{~mm} / \mathrm{s}$ and $60 \mathrm{~mm} / \mathrm{s}$. These scans were conducted on a single sample to create different cooling rates in the melted region. Argon shielding gas was used to minimize oxidation during experiments. A typical sample after the laser experiment is shown in Figure 1(b).

\section{Microstructural and microsegregation characterization}

The laser surface remelted samples were sectioned both along and perpendicular to the scanning direction. Samples were mounted, ground and polished for microstructural characterization using standard sample preparation methods for Al-Cu alloys. Samples were etched in Krolls Solution to observe the microstructural features.

The microstructural characterization was conducted using several techniques. The melt pool shape and size were measured using optical microscopy. Finer microstructural features such as dendrite arm spacing (DAS) and secondary phases were quantitatively measured using Scanning Electron Microscopy (SEM). Grain morphology and growth orientation were characterized using Electron Backscatter Scanning Detector (EBSD)

Quantitative microsegregation was measured using Electron Probe Micro-Analysis (EPMA). A Cameca SX-100 electron microprobe equipped with wavelength-dispersive spectrometers was used in this study. 
The accelerating voltage and beam current were set to $15 \mathrm{kV}$ and $10 \mathrm{nA}$, respectively. The voltage and current were kept relatively low to reduce the beam interaction volume, which improved the measurement accuracy of copper composition in the refined microstructure. Over 400 points were collected across multiple samples, and the microsegregation profile was constructed using the WIRS method [23].

\section{Results}

\section{Microstructural characterization in the melt pool}

Figure 2 shows cross sections of the laser melt pools from optical microscopy. The width and depth of the melt pools varied and were dependent on the laser scan speed. Figure 2(a) shows the melt pool produced by the laser beam with a scan speed of $5 \mathrm{~mm} / \mathrm{s}$. The width and the depth of the melt pool was measured to be 1000um and $375 \mathrm{um}$, respectively. The microstructural features within the melt pool are distinct from the base material and demonstrated that the laser surface remelting altered the microstructure. Two additional representative micrographs of a higher magnification, as shown in the figure, were taken from the top and bottom of the melt pool, respectively. These dendritic microstructure in the melt pool is much finer compared to the base cast and solution treated plate material. The morphology of those melt pool dendrites depended on location within the melt pool and columnar dendrites were observed at the bottom of the melt pool while globular dendrites were observed at the top of the melt pool. A melt pool produced by the laser with a fast scan speed of $60 \mathrm{~mm} / \mathrm{s}$ is shown in Figure 2(b) with a melt pool width of $626 \mathrm{um}$ and a depth of $75 \mu \mathrm{m}$. As the laser scan speed increases, both the width and depth of the melt pool decrease, as well as the dendrite spacing decreases in the melt pool. Different morphologies of the dendrites are also observed at different locations of the melt pool. Globular dendrites, with circular morphology, occupied at the top of the melt pool; while elongated columnar dendrites dominate at the bottom of the melt pool.

The results of SEM characterization, as shown in Figure 3, provided more detailed information on the size and morphology of dendrites and secondary phases in the melt pools. Elongated columnar dendrites were observed at the bottom of the melt pool at both scan speeds of $5 \mathrm{~mm} / \mathrm{s}$ and $60 \mathrm{~mm} / \mathrm{s}$, as shown in Figure 3(a) and (d). At $5 \mathrm{~mm} / \mathrm{s}$, the size of the dendrites is much larger. In additional, fine $\mathrm{Al}_{2} \mathrm{Cu}$ secondary phases can be clearly identified among dendrites at $5 \mathrm{~mm} / \mathrm{s}$. In contrast, at $60 \mathrm{~mm} / \mathrm{s}$, only a few, very fine secondary phase $\mathrm{Al}_{2} \mathrm{Cu}$ particles could be observed. This difference can be attributed to the stronger solute trapping that exists during solidification during the faster laser scan. As the speed increases, solidification rate dramatically increases in the melt pool, which leads to more Cu solute entrapment in the primary phase during solidification and less solute available to form secondary phases. Figure 3(c) and (f) show the microstructural features close to the top of the melt pool. Globular dendrites, which have a circular morphology, dominate at the top of the melt pool at both scanning speeds. The size of the globular dendrites was also dependent on the scan speed and larger and more secondary phase precipitates can be found at $5 \mathrm{~mm} / \mathrm{s}$ compared to the $60 \mathrm{~mm} / \mathrm{s}$. 
At both scan speeds, transitions from columnar dendrites to globular dendrites were observed around the center of the melt pool, which are highlighted in Figure 3(b) and (e). This transition was found in all melt pools, regardless of scan speeds, which indicates the morphology change is independent of the cooling rate.

Quantitative SEM analysis was conducted to measure the dendrite spacing at different scan speeds and different locations of the melt pool, and the results were summarized in Figure 4. Ultra-fine dendrites have a size of 1-4 $\mu \mathrm{m}$, depending on the laser scan speed. As the speeds increase, the spacing of the dendrites continuously decreases. However this dependence on scan speed was not linear and at lower scan speeds, the influence on dendrite spacing was pronounced whereas at high scan speeds, the refinement is only moderate. Dendrite spacing at different locations, including bottom, center, and top of the melt pool, are also shown in Figure 4. Spacing was largest for dendrites at the bottom of the melt pool and smallest at the top. The difference was most significant at low scan speed, which indicate the solidification conditions within the melt pool are location-dependent and this location dependence is more pronounced at low scan speeds.

\section{EBSD Characterization of Melt Pool}

A transition in dendrite morphology from columnar to globular was observed in all melt pools from the bottom region to the top. The transition mechanism was difficult to be directly determined from SEM images, therefore EBSD characterization was used conducted to characterize this transition.

Representative EBSD Inverse Pole Figure (IPF) images of samples from $5 \mathrm{~mm} / \mathrm{s}$ and $60 \mathrm{~mm} / \mathrm{s}$ are shown in Figure 5. The images perpendicular to the laser scanning direction are shown in Figure 5(a-b), and image parallel to the scanning direction are shown in Figure 5(c). Figure 5(a-b) demonstrate an epitaxial grain growth from the melt pool boundary and various grain orientations at the center of the melt pool. The liquid metal at the melt pool boundary appears to initially solidify following the parent grain orientations in the base plate material. As the grains grow towards to the center of the melt pool, new grains of different orientations form and dominate. Figure 5(c) reveals the $\square$ trajectory of grains solidifying in a melt pool parallel to the laser scan direction. The grain growth closely followed the beam movement, and the tail of the grain blocked the growth of the grains underneath. The characterization from two different directions reveals that the grains in the center of the melt pool is not an equiaxed morphology, instead these grains are the tail of previous grains. The morphology change of dendrite experimentally observed is not a columnar-to-equiaxed transition. The shift of dendrite morphology is actually due grain orientation change from bottom of the melt pool to the top. A similar phenomena has also been observed phase field simulation of additive materials produced by the laser powder bed fusion technique [24].

\section{Quantitative measurements of microsegregation during laser remelting}

Cu microsegregation behavior during laser remelting was measured by EPMA and sorted using the weighted interval rank and sort (WIRS) method [23]. The Cu solute profile from samples with scan speed 
of $3 \mathrm{~mm} / \mathrm{s}$ and $5 \mathrm{~mm} / \mathrm{s}$ are shown in Figure $6(\mathrm{a})$. The interaction volume of the beam is around $2 \mu \mathrm{m}$ under the current settings, so the dendrite spacing should be larger than this value in order to capture the Cu microsegregation behavior within dendrites. Therefore, only samples with speed of $3 \mathrm{~mm} / \mathrm{s}$ and 5 $\mathrm{mm} / \mathrm{s}$ were measured, considering the relatively larger dendrite spacing in these melt pools. Cu profiles from $3 \mathrm{~mm} / \mathrm{s}$ and $5 \mathrm{~mm} / \mathrm{s}$ both have a positive slope, which show an increasing of Cu concentration as solid fraction increases. The microsegregation still exists at these scanning speeds, where the $\mathrm{Cu}$ concentration is lowest at the center of the dendrite and becomes higher closer to the interdendritic region. The two profiles are also compared to predictions using the classical Scheil equation. Both profiles deviate significantly from Scheil, as illustrated in Figure 6(a). This deviation can be attributed to the far from equilibrium conditions that exist during the rapid solidification within the melt pool.

A concentration map was also measured by electron micro-probe for both scanning speeds. The scanned area is $30 \times 30 \mu \mathrm{m}$, which includes several columnar dendrites and secondary phases, as shown in Figure $6(\mathrm{~b})$ and (c). The concentration map demonstrates a more direct solute redistribution behavior within the microstructure. A periodic pattern of the Cu concentration value can be found, which is due to solute partitioning during dendritic solidification. A schematic representation of the columnar dendrites was overlayed on the maps for a clearer depiction of solute distribution within the dendrites. At $3 \mathrm{~mm} / \mathrm{s}$, high $\mathrm{Cu}$ content was observed, which indicates the existence of the secondary phase. As scan speed increases to $5 \mathrm{~mm} / \mathrm{s}$, no secondary phase with high Cu concentration was observed in this area. Also, the difference of Cu concentration in the map across dendrites becomes smaller at the higher scan speed. These comparisons indicate a reduced microsegregation degree at the higher speed of $5 \mathrm{~mm} / \mathrm{s}$.

\section{Discussion}

\section{Effects of the laser scan speeds on the microstructures within the melt pool}

Quantitative measurement of the dendrite spacing shows that the laser scan speed influences microstructural quantities. Previous simulation work [25] using heat transfer and fluid flow model shown that the a faster laser scan speeds increased the cooling rate but decreased the thermal gradient in the melt pool. Cooling rate is the key factor that determines the secondary dendrite arm spacing and grain size. A power relationship [26, 27] between the cooling rate and the dendrite size for Al-Cu alloys has been previously observed and is summarized as:

$$
D=54 C R^{-0.35}
$$

Where the $\mathrm{D}$ represents the dendrite spacing (in um) and $\mathrm{CR}$ represents the cooling rate (in ${ }^{\circ} \mathrm{C} / \mathrm{s}$ ). Using the quantitative measurements of dendrite spacing, the cooling rate in the melt pools under different laser conditions was inferred using equation (1). The results are summarized in Table 1 and values of cooling rate vary from $10^{3}-10^{5} \mathrm{C} / \mathrm{s}$. The experimental measured DAS are also comparable to the DAS from phase field prediction of Al-Cu during rapid solidification [25]. 
The thermal parameters also vary spatially within the melt pool. Several thermal simulation studies [25, $28,29]$ have reported location-dependent solidification conditions within melt pools. Cooling rate has generally been found to be slowest at the bottom of the melt pool and became fastest at the top. The dendrites spacing decreases as cooling rate increases, which can explain a smaller spacing at the top of the melt pool.

In addition, the transition in the morphology of the dendrites was observed in the melt pool. This transition was caused by the change of grain orientation due to the laser movement. The grain growth was epitaxial at the bottom of the melt pool, but the grain growth closer to the surface was affected by the thermal gradient of the laser movement.

Table 1

Inferred cooling rate using DAS experimental measurement results

\begin{tabular}{|ll|}
\hline Laser scan speed $(\mathrm{mm} / \mathbf{s})$ & Inferred cooling rate using eq $(\mathbf{1})$ in ${ }^{\circ} \mathrm{C} / \mathbf{s}$ \\
\hline 3 & $2.6 \mathrm{E} 3$ \\
\hline 5 & $5.2 \mathrm{E} 3$ \\
\hline 15 & $1.4 \mathrm{E} 4$ \\
\hline 30 & $2.9 \mathrm{E} 4$ \\
\hline 60 & $5.5 \mathrm{E} 5$ \\
\hline
\end{tabular}

\section{Effects of solidification speeds on microsegregation during rapid solidification}

Microsegregation can be characterized as the amount of solute $(\mathrm{Cu})$ in the solidified material as a function fraction solid - which indicates the moment in time at which the region solidified. As shown in Figure 6(a), comparing microsegregation profiles for scan speeds of $3 \mathrm{~mm} / \mathrm{s}$ and $5 \mathrm{~mm} / \mathrm{s}$, scan speed (cooling rate) has a significant influence on both the initial values and the slopes Both scan speeds produced rapid solidification, which gives rise to solute trapping [30-33]. Solute trapping decreases the Cu partitioning and decreases the amount of microsegregation. Rapid solidification will increase the undercooling at the dendrite tip. As the solidification rate increases, a high undercooling develops at the dendrite tip and the partition coefficient deviates from its equilibrium value. A higher undercooling drives a high initial Cu concentration at the dendrite tip [31], which cause a higher initial Cu value at a scan speed of $5 \mathrm{~mm} / \mathrm{s}$ compared to $3 \mathrm{~mm} / \mathrm{s}$. As cooling rate increases, the value of partition coefficient of $\mathrm{Cu}$ solute will shift closer to 1 [34], which means less microsegregation is observed after solidification. Therefore, the microsegregation degree of the $\mathrm{Cu}$ at $5 \mathrm{~mm} / \mathrm{s}$ is less; and the Cu profile of $5 \mathrm{~mm} / \mathrm{s}$ also has a flatter slope. It is anticipated that this microsegregation information will provide useful information for simulating and modeling the microsegregation of solutes during solidification conditions that are far from equilibrium and that can exist in manufacturing processes such as additive manufacturing and high pressure die casting. 


\section{Conclusion}

In this study, an ultra-fine solidification microstructure was achieved using the LSR technique at scan speeds ranging from $5 \mathrm{~mm} / \mathrm{s}$ to $60 \mathrm{~mm} / \mathrm{s}$. These scan speeds produced solidification rates that were estimated to vary from $2.6 \times 10^{-3}$ to $5.5 \times 10^{-5}{ }^{\circ} \mathrm{C} / \mathrm{s}$. The refined dendrites within the melt pool were experimentally characterized. Dendrite spacing of 1- $4 \mu \mathrm{m}$ was measured at different laser scan speeds and a quantitative relationship was developed. The dendrite morphology was characterized in these melt pools and the morphology transition of the dendrites was not a columnar-to-equiaxed transition but rather a result of the nature of solidification within the rapidly moving melt pool produced by the laser melting. EBSD characterization of the sections parallel and perpendicular to the laser scan direction reveals a transition due to the curved grain growth from bottom towards the top of the melt pool. The microsegregation behavior of $\mathrm{Cu}$ was quantitatively measured in the rapidly solidified melt pool. As expected, the measured microsegregation results significantly deviated from Scheil conditions and suggest a high degree of undercooling and a non-equilibrium partition coefficient during rapid solidification. The Cu microsegregation profile was influenced by the laser scan speed, demonstrating a stronger solute trapping and decreased microsegregation at higher solidification rates.

\section{Declarations}

\section{Data Availability}

The experimental data supporting this publication is available on the Materials Commons at http://doi.org/10.13011/m3-m8qx-ca92

\section{Acknowledgement}

The authors acknowledge with profound gratitude the many helpful discussion and assistance of the late Professor Jyoti Mazumder. His untimely death precluded his assistance in manuscript preparation but this research could not have been conducted without his generosity and insights. We want to acknowledge Yang Huo of Ford Motor Co who assisted in producing the cast plates. We also acknowledge financial assistance from Ford Motor Co.

\section{References}

[1] J. Dutta Majumdar, I. Manna, Laser material processing, Int. Mater. Rev. 56 (2011) 341-388. doi:10.1179/1743280411Y.0000000003.

[2] Q. Lei, B.P. Ramakrishnan, S. Wang, Y. Wang, J. Mazumder, A. Misra, Structural refinement and nanomechanical response of laser remelted Al-Al2Cu lamellar eutectic, Mater. Sci. Eng. A. 706 (2017) 115-125. doi:10.1016/j.msea.2017.08.105. 
[3] Q. Lei, J. Wang, A. Misra, Mechanical behavior of al-al2 cu-si and al-al2 cu eutectic alloys, Crystals. 11 (2021) 1-9. doi:10.3390/cryst11020194.

[4] M.M. Quazi, M.A. Fazal, A.S.M.A. Haseeb, F. Yusof, H.H. Masjuki, A. Arslan, Laser-based Surface Modifications of Aluminum and its Alloys, Crit. Rev. Solid State Mater. Sci. 41 (2016) 106-131. doi:10.1080/10408436.2015.1076716.

[5] W. Kurz, B. Giovanola, R. Trivedi, Theory of microstructural development during rapid solidification, Acta Metall. 34 (1986) 823-830. doi:10.1016/0001-6160(86)90056-8.

[6] S.J. Wang, G. Liu, D.Y. Xie, Q. Lei, B.P. Ramakrishnan, J. Mazumder, J. Wang, A. Misra, Plasticity of laser-processed nanoscale Al-Al2Cu eutectic alloy, Acta Mater. 156 (2018) 52-63. doi:10.1016/j.actamat.2018.06.038.

[7] M. Zimmermann, M. Carrard, W. Kurz, Rapid solidification of Al-Cu eutectic alloy by laser remelting, Acta Metall. 37 (1989) 3305-3313. doi:10.1016/0001-6160(89)90203-4.

[8] S.C. Gill, W. Kurz, Rapidly solidified AlıCu alloys-I. experimental determination of the microstructure selection map, Acta Metall. Mater. 41 (1993) 3563-3573. doi:10.1016/0956-7151(93)90237-M.

[9] S.C. Gill, M. Zimmermann, W. Kurz, Laser resolidification of the AlAl2Cu eutectic: The coupled zone, Acta Metall. Mater. 40 (1992) 2895-2906. doi:10.1016/0956-7151(92)90454-M.

[10] B.P. Ramakrishnan, Q. Lei, A. Misra, J. Mazumder, Effect of laser surface remelting on the microstructure and properties of Al-Al2Cu-Si ternary eutectic alloy, Sci. Rep. 7 (2017) 13468. doi:10.1038/s41598-017-13953-5.

[11] X. Wang, K. Chou, Microstructure simulations of Inconel 718 during selective laser melting using a phase field model, Int. J. Adv. Manuf. Technol. 100 (2019) 2147-2162. doi:10.1007/s00170-018-2814-z.

[12] L. Wang, Y. Wei, F. Yu, Q. Zhang, Q. Peng, Phase-field simulation of dendrite growth under forced flow conditions in an Al-Cu welding molten pool, Cryst. Res. Technol. 51 (2016) 602-609. doi:10.1002/crat.201600165.

[13] F. Yu, Y. Wei, Y. Ji, L.Q. Chen, Phase field modeling of solidification microstructure evolution during welding, J. Mater. Process. Technol. 255 (2018) 285-293. doi:10.1016/j.jmatprotec.2017.12.007.

[14] V. Fallah, M. Amoorezaei, N. Provatas, S.F. Corbin, A. Khajepour, Phase-field simulation of solidification morphology in laser powder deposition of Ti-Nb alloys, Acta Mater. 60 (2012) 1633-1646. doi:10.1016/j.actamat.2011.12.009.

[15] K. Surekha, B.S. Murty, K. Prasad Rao, Comparison of corrosion behaviour of friction stir processed and laser melted AA 2219 aluminium alloy, Mater. Des. 32 (2011) 4502-4508.

doi:10.1016/j.matdes.2011.03.033. 
[16] J.L. de Mol van Otterloo, J.T.M. De Hosson, Laser treatment of aluminium copper alloys: A mechanical enhancement, Scr. Metall. Mater. 30 (1994) 493-498. doi:10.1016/0956-716X(94)90609-2.

[17] H. Badekas, A. Koutsomichalis, C. Panagopoulos, The influence of excimer laser treatment on an aluminium alloy surface, Surf. Coatings Technol. 34 (1988) 365-371. doi:10.1016/0257-8972(88)900941.

[18] M.A. Pinto, N. Cheung, M.C.F. lerardi, A. Garcia, Microstructural and hardness investigation of an aluminum-copper alloy processed by laser surface melting, in: Mater. Charact., Elsevier, 2003: pp. 249253. doi:10.1016/S1044-5803(03)00091-3.

[19] D.W. Heard, R. Gauvin, M. Brochu, Non-equilibrium solute partitioning in a laser re-melted Al-Li-Cu alloy, Acta Mater. 61 (2013) 7432-7436. doi:10.1016/j.actamat.2013.08.050.

[20] S.C. Gill, W. Kurz, Rapidly solidified AlCu alloys-II. Calculation of the microstructure selection map, Acta Metall. Mater. 43 (1995) 139-151. doi:10.1016/0956-7151(95)90269-4.

[21] M. Gremaud, M. Carrard, W. Kurz, The microstructure of rapidly solidified AlaFe alloys subjected to laser surface treatment, Acta Metall. Mater. 38 (1990) 2587-2599. doi:10.1016/0956-7151(90)90271-H.

[22] Y.-J. Liang, X. Cheng, H.-M. Wang, A new microsegregation model for rapid solidification multicomponent alloys and its application to single-crystal nickel-base superalloys of laser rapid directional solidification, Acta Mater. 118 (2016) 17-27. doi:10.1016/j.actamat.2016.07.008.

[23] M. Ganesan, D. Dye, P.D. Lee, A technique for characterizing microsegregation in multicomponent alloys and its application to single-crystal superalloy castings, Metall. Mater. Trans. A. 36 (2005) 21912204. doi:10.1007/s11661-005-0338-2.

[24] A.F. Chadwick, P.W. Voorhees, The development of grain structure during additive manufacturing, Acta Mater. 211 (2021) 116862. doi:10.1016/j.actamat.2021.116862.

[25] A. Farzadi, M. Do-Quang, S. Serajzadeh, A.H. Kokabi, G. Amberg, Phase-field simulation of weld solidification microstructure in an Al-Cu alloy, Model. Simul. Mater. Sci. Eng. 16 (2008). doi:10.1088/0965-0393/16/6/065005.

[26] K.P. Young, D.H. Kerkwood, The dendrite arm spacings of aluminum-copper alloys solidified under steady-state conditions, Metall. Trans. A. 6 (1975) 197-205. doi:10.1007/BF02673688.

[27] T.D. Berman, Z. Yao, E. Deda, L. Godlewski, M. Li, J.E. Allison, Measuring and modeling microsegregation in high pressure die cast Mg-Al Alloys, Metall. Mater. Trans. A. (n.d.).

[28] S. Liu, H. Zhu, G. Peng, J. Yin, X. Zeng, Microstructure prediction of selective laser melting AlSi10Mg using finite element analysis, Mater. Des. 142 (2018) 319-328. doi:10.1016/j.matdes.2018.01.022. 
[29] A. Raghavan, H.L. Wei, T.A. Palmer, T. DebRoy, Heat transfer and fluid flow in additive manufacturing, J. Laser Appl. 25 (2013) 052006. doi:10.2351/1.4817788.

[30] P.M. Smith, M.J. Aziz, Solute trapping in aluminum alloys, Acta Metall. Mater. 42 (1994) 35153525. doi:10.1016/0956-7151(94)90483-9.

[31] B. Giovanola, W. Kurz, Modeling of microsegregation under rapid solidification conditions, Metall. Trans. A. 21 (1990) 260-263. doi:10.1007/BF02656445.

[32] T. Pinomaa, M. Lindroos, M. Walbrühl, N. Provatas, A. Laukkanen, The significance of spatial length scales and solute segregation in strengthening rapid solidification microstructures of $316 \mathrm{~L}$ stainless steel, Acta Mater. 184 (2020) 1-16. doi:10.1016/j.actamat.2019.10.044.

[33] V. Bathula, C. Liu, K. Zweiacker, J. McKeown, J.M.K. Wiezorek, Interface velocity dependent solute trapping and phase selection during rapid solidification of laser melted hypo-eutectic Al-11at.\%Cu alloy, Acta Mater. 195 (2020) 341-357. doi:10.1016/j.actamat.2020.04.006.

[34] M.J. Aziz, Model for solute redistribution during rapid solidification, J. Appl. Phys. 53 (1982) 11581168. doi:10.1063/1.329867.

\section{Figures}

(a)
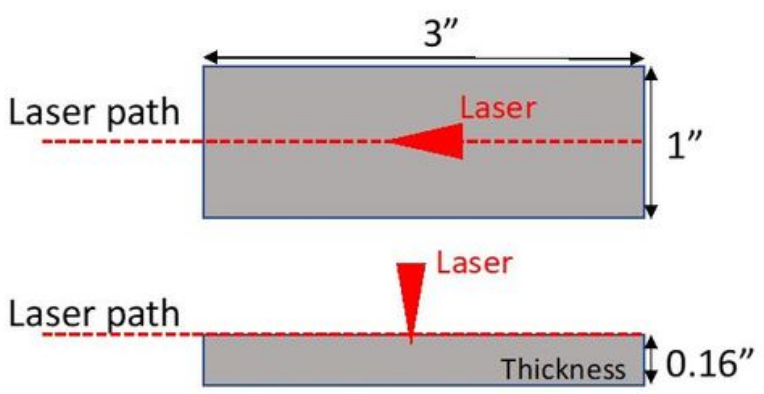

(b)

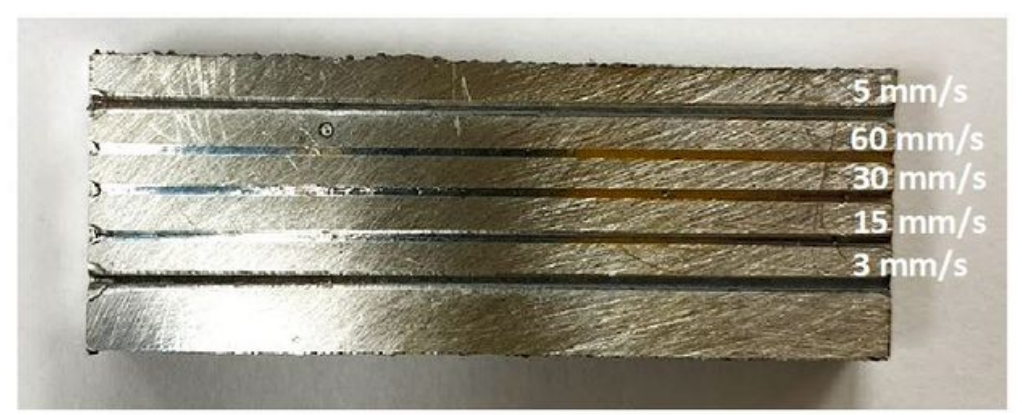

\section{Figure 1}

(a) Schematic representation of the dimensions of Al-3Cu samples for laser surface remelting experiment and the laser beam path during the experiment. (b) Image of a typical sample after laser surface remelting. Several laser scans with different scanning speeds were conducted on the same sample. 
(a)

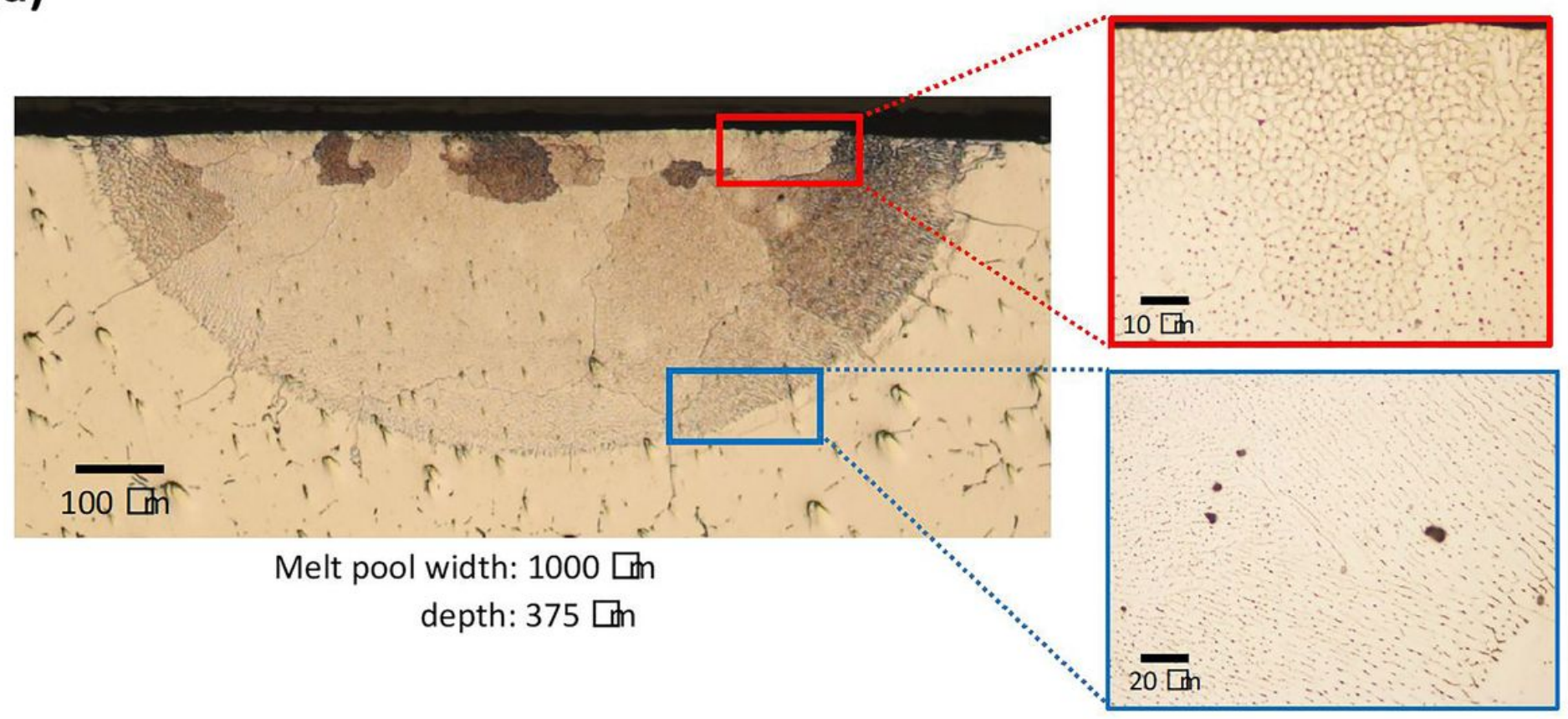

(b)

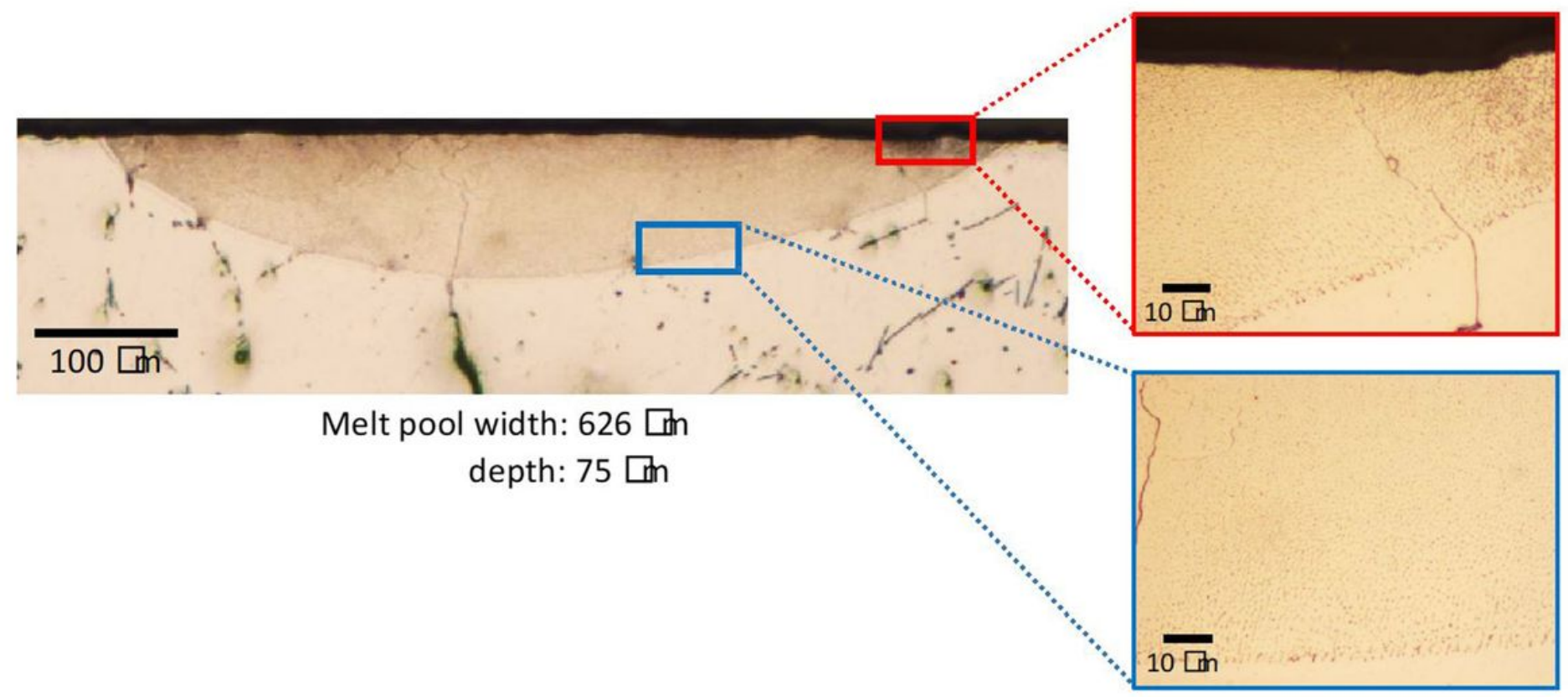

Figure 2

Optical micrograph of melt pools induced by laser beam with different scanning speed (a) $5 \mathrm{~mm} / \mathrm{s}$ and (b) $60 \mathrm{~mm} / \mathrm{s}$. Two additional micrographs at a higher magnification from each condition show the different morphologies of the dendrites at the bottom and top of the melt pool 


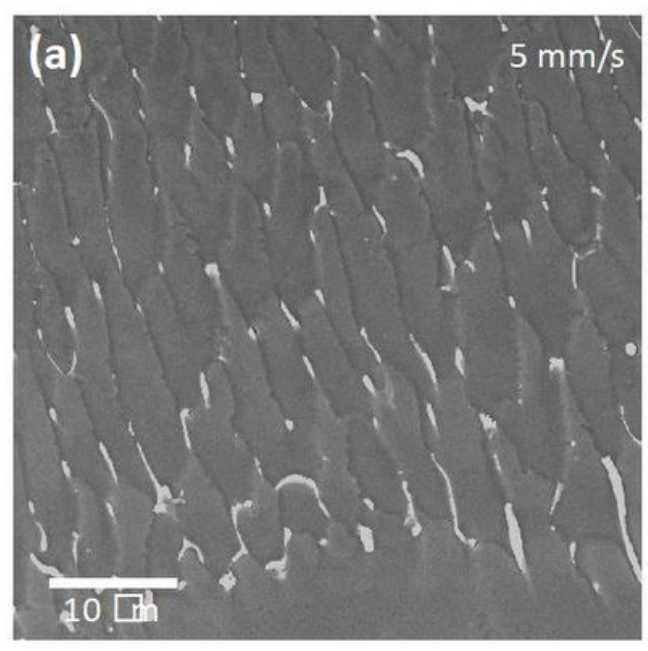

Bottom of melt pool

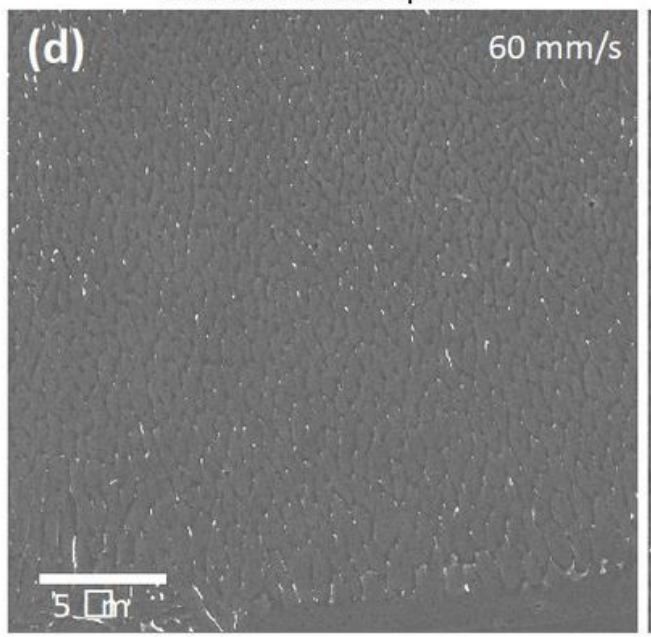

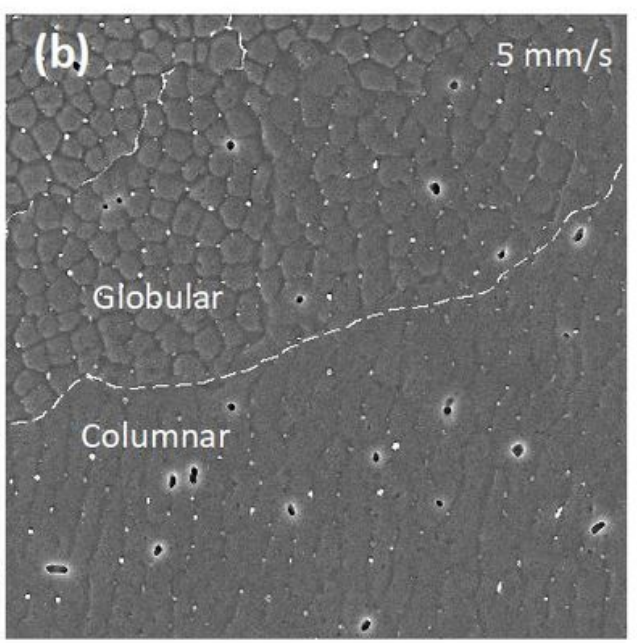

Middle of melt pool

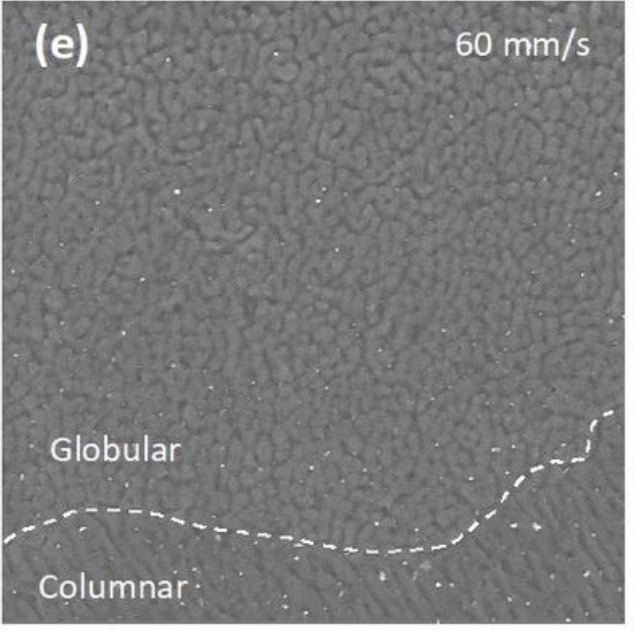

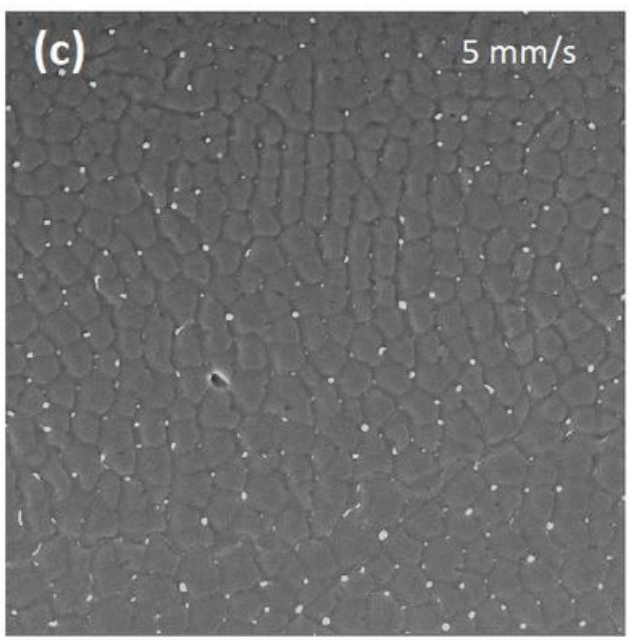

Surface of melt pool

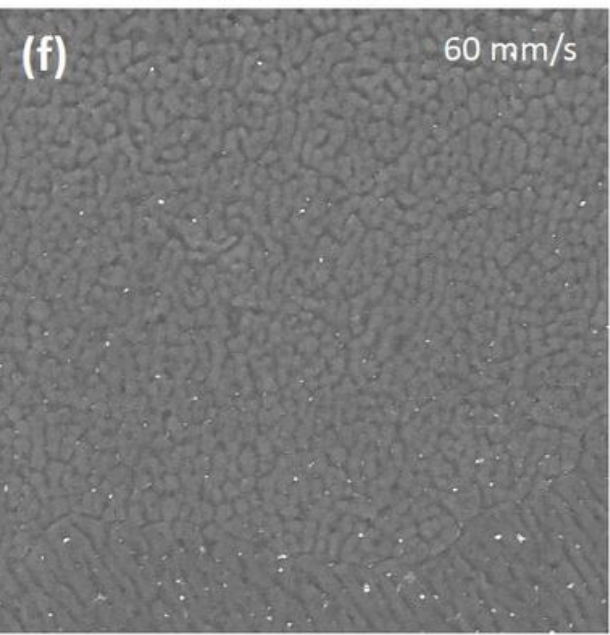

\section{Figure 3}

SEM characterization of the dendrite morphology within the melt pool. (a-c) The melt pool was from LSR with a laser scan speed of $5 \mathrm{~mm} / \mathrm{s}$. While (d-f) shows the LSR melt pool with a laser scan speed of $60 \mathrm{~mm} / \mathrm{s}$. The views are from the bottom, center and top of the melt pool, respectively. 


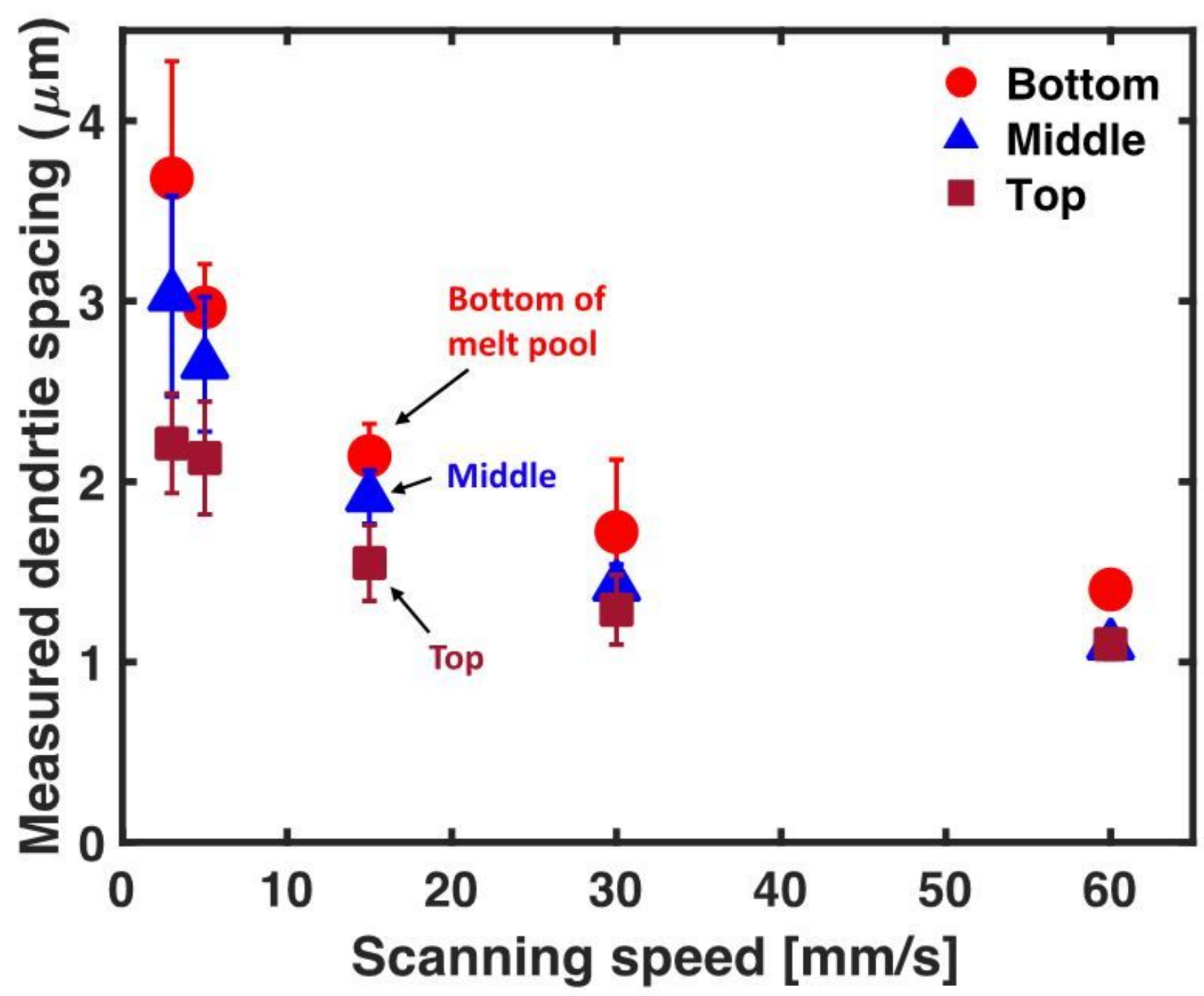

Figure 4

Quantitative measurements of dendrite spacing within the melt pool at different laser scan speeds. The dendrite spacing decreases as scan speed increases. Dendrite spacings measured at different locations within a melt pool (bottom, center and top of the melt pool, respectively) were also compared. 


\section{(a) $5 \mathrm{~mm} / \mathrm{s}$}

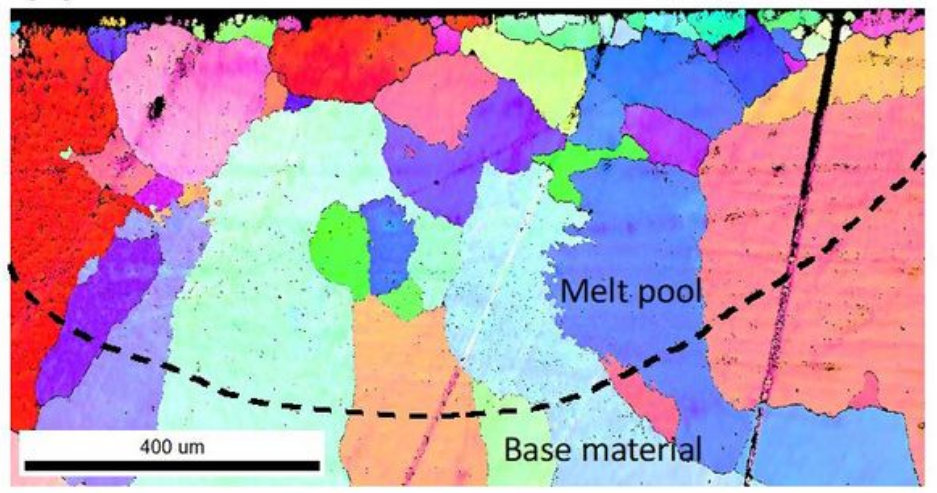

(b) $60 \mathrm{~mm} / \mathrm{s}$

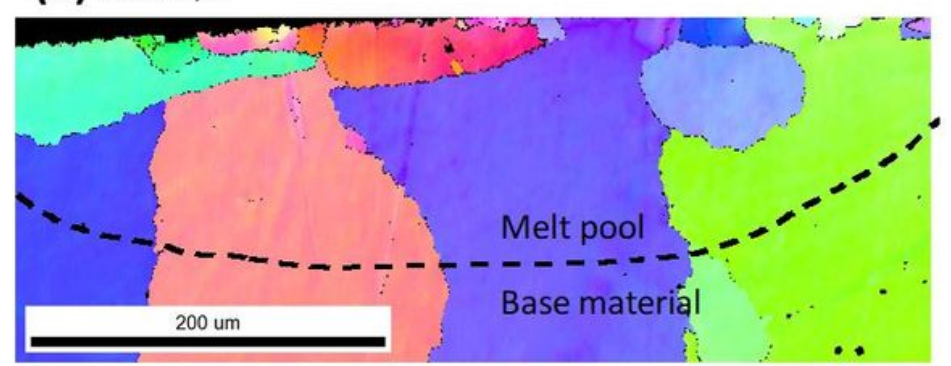

(c)

Laser

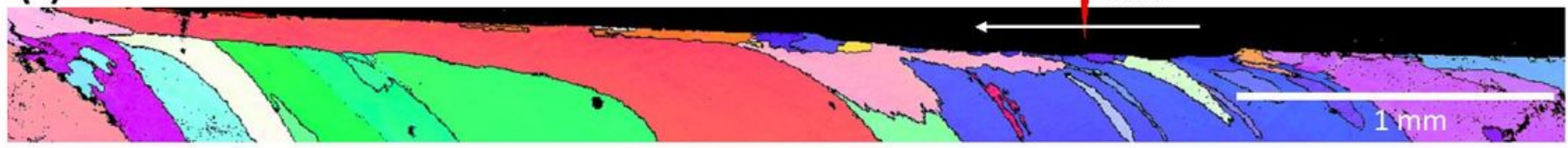

\section{Figure 5}

EBSD characterization of the cross section of the melt pool along the laser scanning direction (a) melt pool with scan speeds of $5 \mathrm{~mm} / \mathrm{s}$ and (b) $60 \mathrm{~mm} / \mathrm{s}$. (c) An EBSD scan performed along the laser scan direction, demonstrating the microstructure features along the scan path.
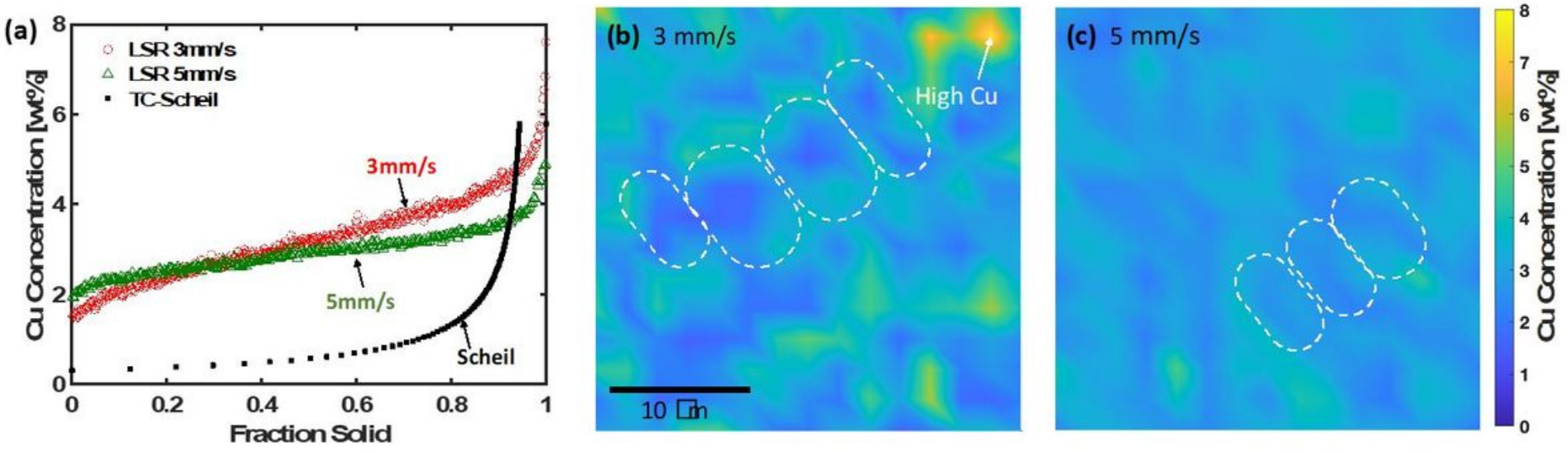

\section{Figure 6}

(a) Cu solute microsegregation profiles at laser scan speeds of $3 \mathrm{~mm} / \mathrm{s}$ and $5 \mathrm{~mm} / \mathrm{s}$ compared with microsegregation predictions assuming Scheil solidification conditions, $(b, c)$ EPMA concentration maps demonstration the $\mathrm{Cu}$ spatial distribution, with low $\mathrm{Cu}$ concentration at the center of the dendrite and high $\mathrm{Cu}$ in the interdendritic region. 